\title{
Cohesive Laws and Progressive Damage Analysis of Composite Bonded Joints, a Combined Numerical/Experimental Approach
}

\author{
Donato Girolamo ${ }^{1}$ \\ National Institute of Aerospace, NASA Langley Research Center, Hampton,VA, 23681, USA \\ Carlos G. Dávila, Frank A. Leone, Shih-Yung Lin \\ NASA Langley Research Center, Hampton, VA, 23681, USA
}

The results of an experimental/numerical campaign aimed to develop progressive damage analysis (PDA) tools for predicting the strength of a composite bonded joint under tensile loads are presented. The PDA is based on continuum damage mechanics (CDM) to account for intralaminar damage, and cohesive laws to account for interlaminar and adhesive damage. The adhesive response is characterized using standard fracture specimens and digital image correlation (DIC). The displacement fields measured by DIC are used to calculate the J-integrals, from which the associated cohesive laws of the structural adhesive can be derived. A finite element model of a sandwich conventional splice joint (CSJ) under tensile loads was developed. The simulations, in agreement with experimental tests, indicate that the model is capable of predicting the interactions of damage modes that lead to the failure of the joint.

\begin{tabular}{|c|c|c|c|}
\hline \multicolumn{4}{|c|}{ Nomenclature } \\
\hline$L, b$ & $\begin{array}{l}\text { half-length and width of DCB, ENF, } \\
\text { and MMB specimens }\end{array}$ & $\delta_{n}, \delta_{t}$ & 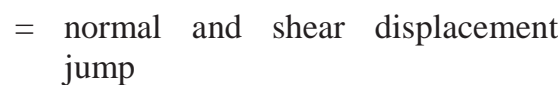 \\
\hline$a_{0}$ & $\begin{array}{l}=\text { initial crack length in the DCB, ENF } \\
\text { and MMB specimens }\end{array}$ & $E_{a d h}, G_{a d h}$ & $\begin{array}{l}=\begin{array}{l}\text { Young's and shear modulus of the } \\
\text { adhesive }\end{array}\end{array}$ \\
\hline$h$ & $\begin{array}{l}=\text { thickness of the composite beams in } \\
\text { the DCB, ENF and MMB specimens }\end{array}$ & $w^{\prime}$ & $\begin{array}{l}=\text { rotation of the composite arm at the } \\
\text { crack tip }\end{array}$ \\
\hline$h_{a d h}$ & $\begin{array}{l}=\text { adhesive layer thickness in the DCB, } \\
\text { ENF and MMB specimens }\end{array}$ & $K_{n}, K_{t}$ & $\begin{aligned} &= \text { penalty stiffness in the normal and } \\
& \text { shear direcions }\end{aligned}$ \\
\hline$B$ & mixed mode ratio & $\sigma, \tau$ & $=$ tensile and shear stress \\
\hline$G_{I c}, G_{I I c}$ & $\begin{array}{l}\text { mode I and mode II critical energy } \\
\text { release rate }\end{array}$ & $\sigma_{n}^{i}, \tau^{i}$ & $\begin{array}{l}=\begin{array}{l}\text { critical stress in the normal and } \\
\text { shear direction }\end{array}\end{array}$ \\
\hline$J_{D C B}, J_{E N F}$ & DCB and ENF J-integral & $U, V$ & $=$ displacement components \\
\hline & applied load & $\eta$ & $=$ Benzeggagh-Kenane coefficient \\
\hline$\Delta$ & displacement modulus & $x, y, z$ & $=$ orthogonal coordinate system \\
\hline
\end{tabular}

\section{Introduction}

\begin{abstract}
A DHESIVE bonded joints possess a number of advantages compared to mechanically fastened joints, especially in the assembly of large composite structures. Bonded joints provide lower structural weight, lower manufacturing costs and improved damage tolerance [1]. However, a lack of reliable material models and failure criteria leads to overdesigning composite structures and composite structural assemblies. The assessment of failure modes, the measurement of material fracture properties and the development of reliable numerical tools to simulate the behavior of the component before and during damage propagation is expected to result in more efficient use of composites and adhesives.

The emphasis of the present work is on adhesive characterization and the development of a progressive damage model for bonded joints in sandwich structures. The joint design considered in this study, conceptually similar to those of the Heavy Lift Launch Vehicles (HLLVs) assemblies, is a composite conventional splice joint (CSJ) designed at NASA-LaRC [2] to bond sandwich panels.
\end{abstract}

${ }^{1}$ Corresponding author, donato.girolamo@nasa.gov 
The CSJ, Figure 1, consists of two sandwich panels joined with two $69.9 \mathrm{~mm}$ long, six-ply splices bonded to the exterior faces of the sandwich with an adhesive layer. The sandwich panels are composed of six-ply TE-1 Grade 190 Type 35 carbon/epoxy facesheets bonded with a Cytec ${ }^{\circledR}$ FM-300M adhesive to a $25.4 \mathrm{~mm}$ thick aluminum honeycomb core. The core material is Hexcel CR III 1/8-5052-.0007. The facesheet plies each have a nominal thickness of $0.19 \mathrm{~mm}$. The stacking sequence of the facesheets is $\left[+60^{\circ} / 0^{\circ} /-60^{\circ}\right] \mathrm{s}$. At their thickest, the splices have the same stacking sequence as the facesheets. Additionally the splices have internal ply terminations and ply drops, and the cascading ply terminations are separated by $6.4 \mathrm{~mm}$. The CSJ specimens is $559 \mathrm{~mm}$ long and $76.2 \mathrm{~mm}$ wide.

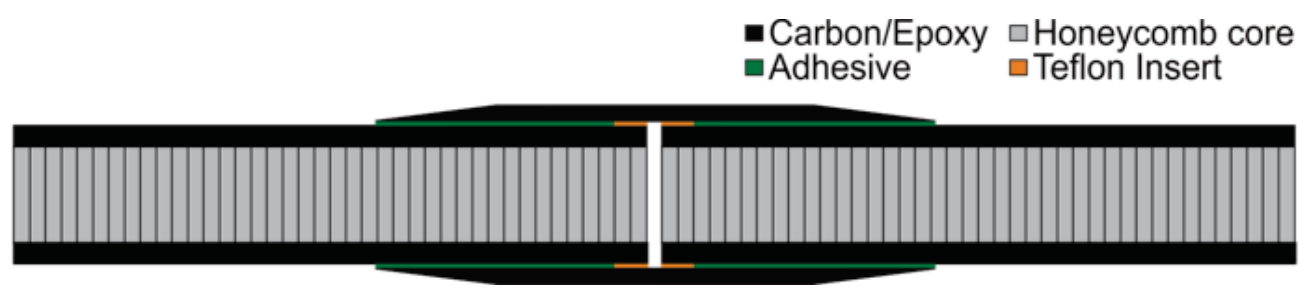

Figure 1. Schematic of the conventional splice joint.

Design specifications for the joint specimens allow for a $2.54 \mathrm{~mm}$ gap between the sandwich panels, although during the analysis it is assumed that the two sandwich panels are initially in contact. To decrease the severity of the stress concentration in the splice near the gap between panels, a $12.7 \mathrm{~mm}$ Teflon film is inserted in-line with the adhesive layer at the joint gap.

The following sections of the paper describe the experimental and numerical work required to develop a strength prediction capability of the CSJ under tensile loads. Section II describes the procedure followed to characterize, from standard fracture tests, the mode I, mode II and mixed mode I-II cohesive laws of the FM-300M adhesive. The cohesive laws capture the linear elastic and softening behaviour of the structural adhesive prior to fracture. Cohesive zone models (CZM) are used to simulate the fracture tests and to validate the models with experimental results. Section III focuses on the PDA of the CSJ: the cohesive laws measured in Section II are applied to model damage of the joint's adhesive; a continuum damage model and a cohesive zone model address intralaminar and interlaminar damage respectively, in the carbon/epoxy facesheets and splices; a one-dimensional damage model [2] simulates crushing of the honeycomb core. In Section IV results of the PDA are reported and compared with the results of an experimental test campaign conducted at NASA Langley [3] on the CSJ. Final remarks, in Section V, conclude the paper.

\section{FM-300M Adhesive Characterization}

In order to perform a complete PDA of bonded composite assemblies, it is necessary to characterize the response of the adhesive in the hardening as well as the softening ranges, up to the point of complete surface separation. A number of test procedures have been proposed to investigate the cohesive failure of adhesives and/or measure the material cohesive laws in different modes of failure. For instance Breitzman [4] obtained the tensile and shear properties of the FM-300M structural adhesive by testing a block of material under axial and shear loading.

An alternative to the characterization of adhesives based on their stress-strain response is to perform fracture tests. These tests are designed to characterize the propagation of damage in terms of fracture toughness, i.e. the critical energy release rate (CERR) and, if designed in order to have a stable crack propagation in the specimen, they allow to characterize the behavior of the material up to complete surface separation.

\section{A. Fracture Specimens}

ASTM provides three standard test procedures to characterize interlaminar fracture toughness of unidirectional fiber reinforced polymer matrix composites: Double Cantilever Beam (DCB) for mode I delamination, End Notch Flexure (ENF) for mode II delamination and Mixed Mode Bending (MMB) for mixed mode I-II delamination.

The standard specimens are modified by embedding an FM-300M adhesive layer between the unidirectional composite arms, as shown in Figure 2, in order to investigate the adhesive fracture mechanics. A Teflon insert is placed at one end of each specimen between the composite arms in order to have an initial crack. The dimensions of the specimens are reported in Table 1.

Nine DCB and eleven ENF specimens with an embedded FM-300M adhesive layer and initial crack length $\mathrm{a}_{0}$ are tested to determine mode I and mode II cohesive laws for the adhesive. To determine the mixed mode I-II cohesive laws, ten MMB specimens are tested at different mixed-mode ratios (defined as the portion of energy dissipated in pure mode II cohesive failure [5]) $B=24 \%, 48 \%, 57 \%$ and $74 \%$. The CERR is a function of the mode mixity: it 
increases monotonically from $\mathrm{G}_{\mathrm{Ic}}$ to $\mathrm{G}_{\mathrm{II}}$. Several empirical models have been proposed to describe this function. Herein, the mixed-mode fracture toughness is described using the Benzeggagh-Kenane (B-K) criterion [6]. Additional details on the configuration of the tests are provided in [7].

Table 1. Specimen dimensions.

\begin{tabular}{rrcccccc}
\hline & & DCB & ENF & MMB 24\% & MMB 48\% & MMB 57\% & MMB 74\% \\
\hline $\mathrm{L}$ & {$[\mathrm{mm}]$} & 130 & 100 & 70 & 70 & 100 & 100 \\
\hline $\mathrm{b}$ (width) & {$[\mathrm{mm}]$} & 25 & 25 & 25 & 25 & 25 & 25 \\
\hline $\mathrm{a}_{0}$ & {$[\mathrm{~mm}]$} & 20 & 35 & 30 & 30 & 45 & 45 \\
\hline $\mathrm{h}$ & {$[\mathrm{mm}]$} & 1.5 & 2.5 & 1.5 & 1.5 & 2.5 & 2.5 \\
\hline $\mathrm{c}$ & {$[\mathrm{mm}]$} & $/ /$ & $/ /$ & 114 & 60 & 73 & 59 \\
\hline $\mathrm{h}_{\mathrm{adh}}$ & {$[\mathrm{mm}]$} & 0.254 & 0.254 & 0.254 & 0.254 & 0.254 & 0.254 \\
\hline
\end{tabular}

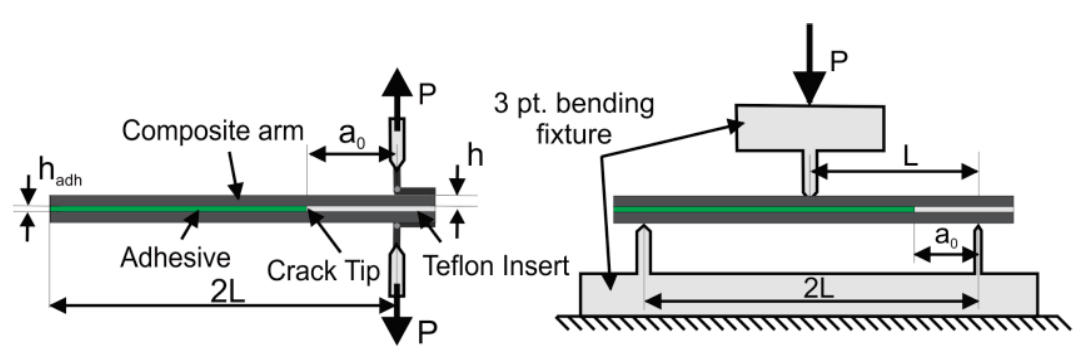

(a) DCB

(b) ENF

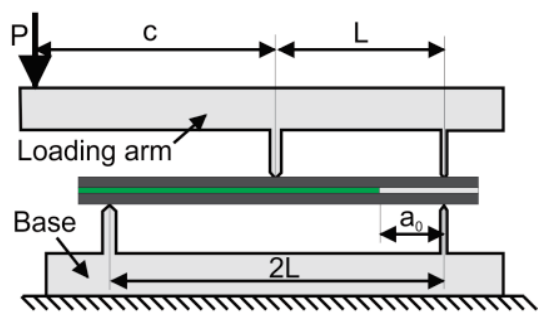

(c) MMB

Figure 2. (a) DCB, (b) ENF and (c) MMB test configurations.

\section{B. Derivation of Cohesive Laws from J-Integrals}

The ASTM DCB, ENF and MMB standard test procedures provide data reduction techniques to extract the critical energy release rate (CERR) from experimental results. However, these techniques, which were developed for delamination in composites, are based on a linear elastic fracture mechanics (LEFM) approach which assumes that no material nonlinearities are present elsewhere than the crack tip. Therefore, the data reduction techniques neglect the extension of the volume ahead of the crack tip in which the material response is non-linear (i.e. the damage process zone). This may lead to inaccurate values of the CERR for materials that develop large process zones.

Nonlinear Fracture Mechanics (NLFM) becomes necessary when the material is subjected to irreversible nonlinearities, or the fracture process zone (FPZ) is not negligibly small compared to the structural dimensions and must be taken into account. The J-integral is an analysis technique used to calculate the fracture energy in problems for which the assumptions of LEFM do not hold. It consists of a contour integral whose value is equal to the energy release rate (ERR), or work per fracture area, in a body that contains a crack. Rice [8] showed that the J-integral has three main properties:

1) It is path independent, i.e., integration along any closed contour surrounding the process zone is constant;

2) Its value is equal to the energy released in the process of damaging a nonlinear elastic body;

3) Its derivative with respect to the displacement jump at the crack tip represents the cohesive law.

The first property of the J-integral allows the selection of the most convenient path along which to integrate the stresses and evaluate the integral. The second property allows for the determination of the ERR from the tests, and the third property is used to extract the shape of the cohesive law. The current work focuses on the experimental estimation of the J-integral for the DCB and ENF tests.

A number of closed-form expressions for the J-integral have been developed based on analytical models of beams on inelastic foundations. Leffler [9] proposed the following expression for the J-integral estimated for the ENF specimen:

$$
J_{E N F} \approx \frac{9}{16} \frac{P^{2} a_{0}^{2}}{E b^{2} h^{3}}+\frac{3}{8} \frac{P \delta_{t}}{b h}
$$

where $E$ is the Young's modulus of the adherends in the fiber direction, assuming unidirectional layup of the specimens, $h$ is the thickness of each arm, $b$ is the width of the specimen, $a_{0}$ is the initial crack length, $\delta_{t}$ is the displacement jump in the shear direction, and $P$ is the applied load. 
A closed form solution for the J-integral for the DCB test is provided by Högberg [10]:

$$
J_{D C B}=\frac{12}{E h}\left(\frac{P a_{0}}{b h}\right)^{2}+\frac{P}{b}\left|w_{\text {top }}^{\prime}-w_{\text {bottom }}^{\prime}\right|
$$

where $w_{\text {top }}^{\prime}$ and $w^{\prime}$ bottom represent the rotation of the top and bottom arm at the crack tip respectively.

The values of the J-integrals for mode II and mode I, given by Equations (1) and (2), can be determined experimentally by measuring the displacement jump $\delta_{t}$ and the rotation $w^{\prime}$ of the arms. A stereoscopic digital image correlation system was used to measure the displacement fields on the profile of the specimens near the crack tip during the tests. Figure 3(a) shows contour plots of the displacement component along the $\mathrm{X}$ axis, U, measured on the edge of an ENF specimen before loading (top figure) and at the instant prior to total separation (bottom figure). The displacement is interrogated along the red lines that are drawn at the crack tip perpendicular to the composite arms through the thickness. After removal of the rigid body rotations, the displacement $U$ as a function of the throughthickness position has the distribution shown in Figure 3(b). The discontinuity of this distribution represents the displacement jump, $\delta_{t}$. This process is performed for all of the images from the initial stage to the total separation point, and for each image the displacement jump is associated to the corresponding applied load, $P$. By substituting the displacement jumps into Equation (1), the J-integral results, shown in Figure 3(c), are obtained. Finally, the cohesive law for mode II is obtained by taking the derivative of the J-integral with respect to the displacement jump. The resulting cohesive laws obtained from three ENF specimens are shown in Figure 3(d).

A similar procedure is followed for the DCB specimens. The displacements from which the rotations of the composite arms are calculated are outlined in Figure 4(a) for the top beam. The shapes of the DCB specimen before and after the application of the load are shown in Figure 4(b). The rotation of the top composite arms, $W_{t o p}^{\prime}$, is highlighted by the relative displacements of two points, $\mathrm{P}_{1}$ and $\mathrm{P}_{2}$ that define the normal directions of the composite arm. The J-integral results obtained using Equation (2) for three DCB specimens are shown in Figure 4(c). The resulting mode I cohesive laws are shown in Figure 4(d).

The area under a cohesive curve corresponds to the maximum value of its J-integral, and this value is the CERR for the material. From the cohesive laws measured for the DCB and ENF specimens the following maximum values of the adhesive CERR and strengths are determined: $\mathrm{J}_{\mathrm{DCB}-\max }=\mathrm{G}_{\mathrm{Ic}} \approx 1.25 \mathrm{~N} / \mathrm{mm}$ and $\mathrm{J}_{\mathrm{ENF}-\max }=\mathrm{G}_{\mathrm{IIc}} \approx 7.9 \mathrm{~N} / \mathrm{mm}$. The maximum stress value of a cohesive curve corresponds to the material strength. The strengths for modes I and II obtained from the cohesive laws as well as the initial part of the cohesive laws are in good agreement with the experimental observations of Breitzman [4], which are shown with the violet curves in Figure 3(d) and Figure 4(d).

It can be observed that the mode I and mode II cohesive laws exhibit different material responses at different stages of their deformation histories:

1) the first part of each law is a linear-elastic domain in which the curve can be approximated by a straight line having a slope of $\mathrm{K}_{\mathrm{n}} \cong 12.4 \mathrm{~N} / \mathrm{mm}^{3}$ for mode I and $\mathrm{K}_{\mathrm{t}} \cong 4.3 \mathrm{~N} / \mathrm{mm}^{3}$ for mode II.

2) The mode II cohesive law includes a second part consisting of a non-linear plastic domain in which the local tangent of the curve is almost horizontal.

3) The final part of each law is a softening domain in which the material is subjected to large separations and unable to withstand the applied tractions.

Curve-fit approximations of the experimental mode I and mode II cohesive laws could be tabulated for use as inputs to cohesive models. However, the authors are not aware of any procedures for establishing mixed-mode cohesive laws from tabulated mode I and mode II data. On the other hand, methods for obtaining mixed-mode cohesive laws from bilinear laws are well established [11]. To take advantage of the available bilinear models, the experimental mode I and II cohesive laws are each approximated by superposing two bilinear curves, referred to as Law A and Law B in Figure 3(d) and Figure 4(d). Therefore, the mode I response is represented by the sum of the bilinear laws $\mathrm{A}^{\mathrm{I}}$ and $\mathrm{B}^{\mathrm{I}}$, and the mode II response is represented by the sum of laws $\mathrm{A}^{\mathrm{II}}$ and $\mathrm{B}^{\mathrm{II}}$. The bilinear laws are defined through the parameters listed in Table 2. Additional details on this methodology are provided by Girolamo [7].

Table 2. Parameters for the bilinear cohesive laws.

\begin{tabular}{|c|c|c|c|c|c|c|}
\hline \multirow[b]{3}{*}{$K_{n}$} & \multirow[b]{3}{*}[\mathrm{N}/\mathrm{mm}^{3}]{} & \multicolumn{2}{|c|}{ Mode I } & & \multicolumn{2}{|c|}{ Mode II } \\
\hline & & Law $A^{I}$ & Law $\mathbf{B}^{\mathrm{I}}$ & & Law $\mathbf{A}^{\text {II }}$ & Law B $\mathbf{B}^{\text {II }}$ \\
\hline & & 11,500 & 1,000 & $K_{t} \quad\left[\mathrm{~N} / \mathrm{mm}^{3}\right]$ & 4,000 & 180 \\
\hline$\sigma_{n}{ }^{i}$ & {$[\mathrm{MPa}]$} & 88 & 1.24 & {$[\mathrm{MPa}]$} & 45 & 21 \\
\hline$G_{I c}$ & {$[\mathrm{~N} / \mathrm{mm}]$} & 1 & 0.25 & $G_{\text {IIc }} \quad[\mathrm{N} / \mathrm{mm}]$ & 4 & 3.9 \\
\hline
\end{tabular}

American Institute of Aeronautics and Astronautics 


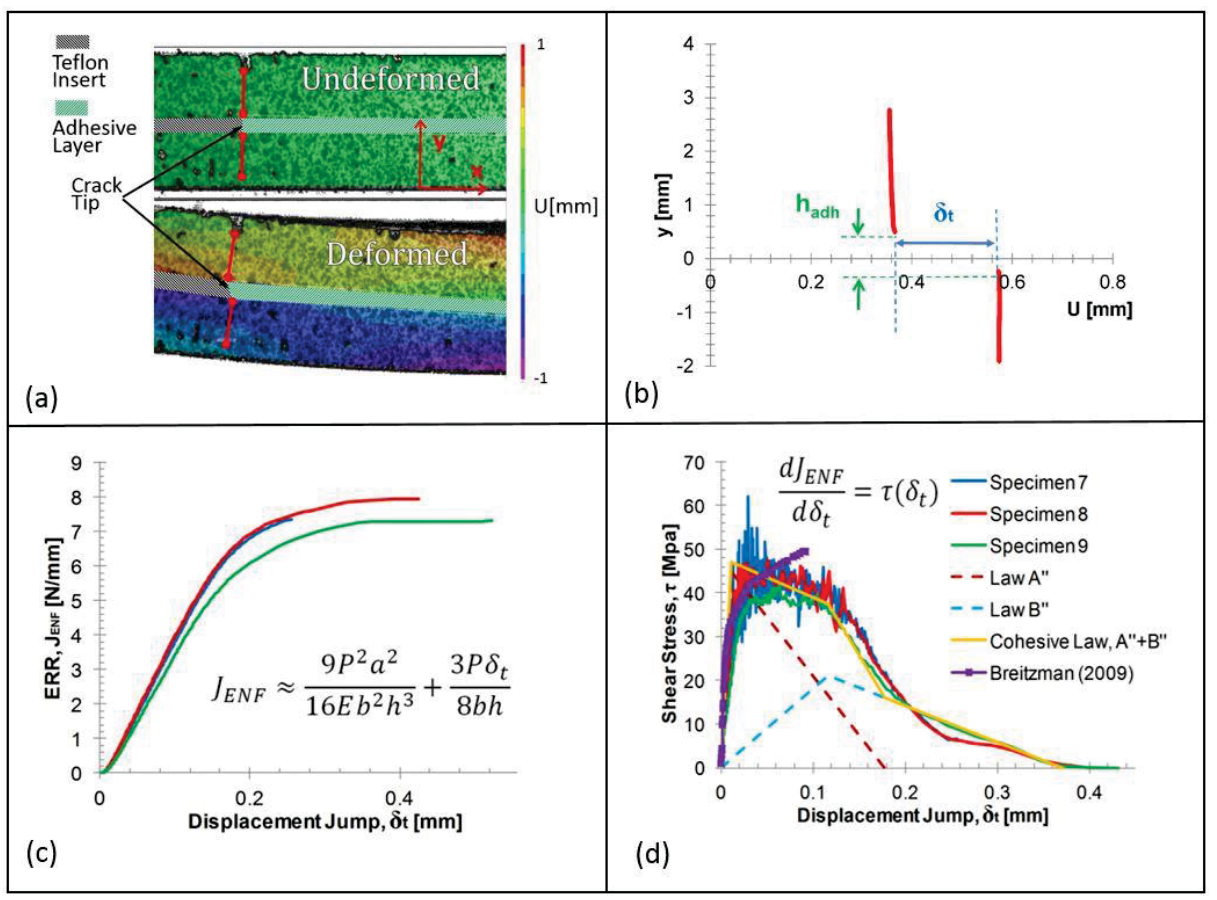

Figure 3. Procedure to determine the mode II cohesive law: (a) displacement field around the crack tip; (b) shearing deformation and displacement jump; (c) J-integral vs. displacement jump; and (d) experimental cohesive law and numerical approximation through bilinear laws.

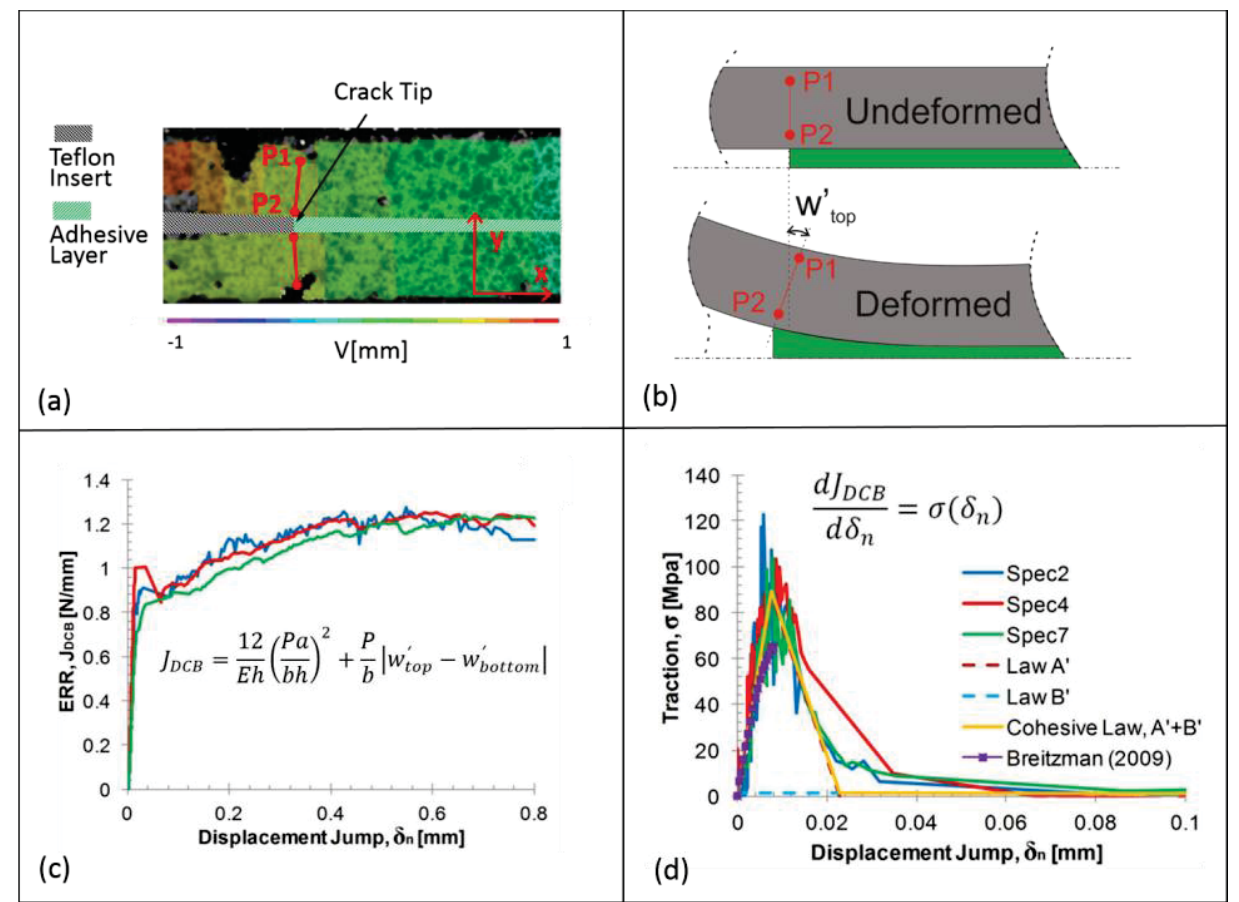

Figure 4. Procedure to estimate the mode I cohesive law: (a) displacement field; (b) rotation of the top composite arm; (c) J-integral vs. displacement jump; and (d) experimental cohesive law and numerical approximation through bilinear laws. 


\section{Finite Element Models of the Adhesive Fracture Tests}

Two-dimensional parametric finite element models of the DCB, ENF and MMB fracture specimens were created for the commercial finite element program Abaqus/Std 6.10 [18], which uses an implicit solution procedure. The models were composed of plain strain CPE4 elements for the composite plies and two superposed layers of finitethickness cohesive elements, Abaqus COH3D8 elements, for the adhesive laws A and B. Further details on the models are provided in [7].

Implicit schemes tend to have convergence difficulties in problems with material softening, and these difficulties are often alleviated by using viscous damping and viscoelastic regularization. However, in the present analyses all artificial damping terms were set to zero to ensure that the models dissipate the correct amount of fracture energy.

DCB, ENF and MMB finite element models are composed of three sections, as shown in Figure 5 for a DCB model. Section AB corresponds to the initial crack, section BC has a fine mesh for accurate prediction of crack propagation, and section $\mathrm{CD}$ has a coarse mesh that does not influence the results since the simulation is stopped before damage reaches it. In section BC, the element size in the $\mathrm{x}$-direction is approximately $0.51 \mathrm{~mm}$. Five elements through the thickness of each arm are sufficient to maintain an aspect ratio of less than 2.5 throughout the model.

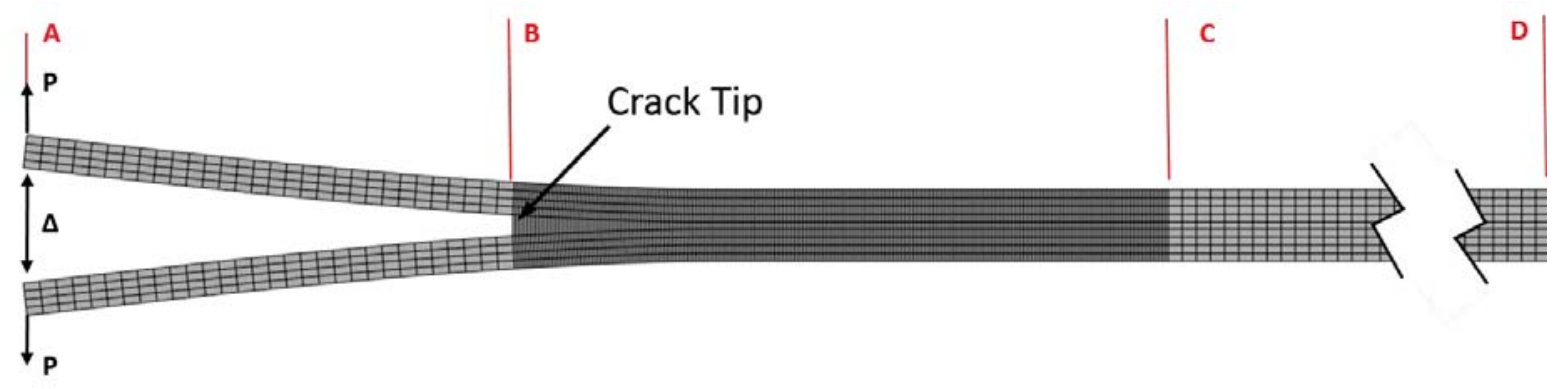

Figure 5. DCB numerical model with mesh, opening displacement, $\Delta$, and applied load, $P$.

The numerical results are reported in terms of applied loads vs. displacements in Figure 6 (red dashed lines) together with the experimental results (black lines) and analytical solutions (blue-dashed lines). The analytical solutions are based on LEFM assumptions [12]. It can be observed that there is a good agreement between experimental and numerical results both in terms of maximum applied load and load-displacement history. As expected, the analytical solutions, based on LEFM, give an overestimation of the maximum applied load and a sharper drop of the load-displacement curves after the maximum is reached. It is worth to underline that some of the MMB and DCB tests show a load drop that is unlike the gradual load reduction exhibited by the numerical simulations. This sudden load drop was caused by the formation of a delamination in the composite. This situation, which is referred to herein as "double delamination", has been addressed in [7].

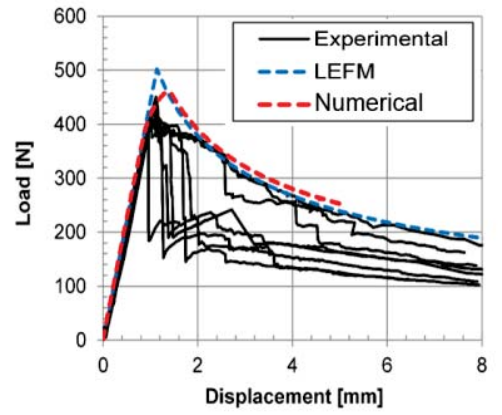

(a) DCB

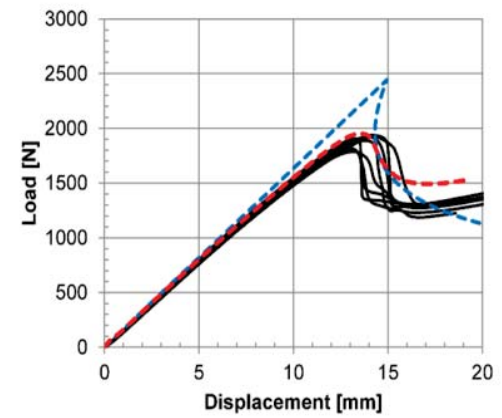

(b) ENF

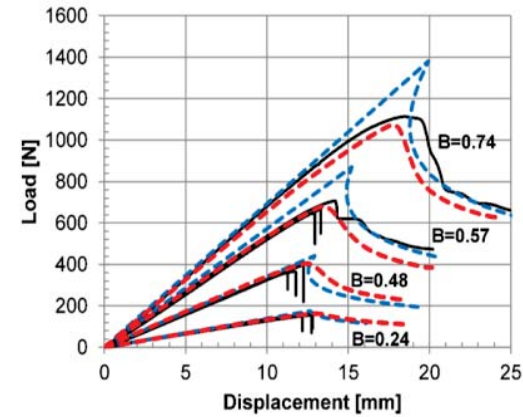

(c) MMB

Figure 6. Experimental, analytical and numerical results for the (a) DCB, (b) ENF and (c) MMB tests.

\section{Progressive Damage Analysis of the Conventional Splice Joint}

As with any composite structure, the sandwich panel joints considered herein have the potential to exhibit several simultaneous failure mechanisms. For example, fiber fracture and intraply matrix cracking can occur within the carbon/epoxy plies, mixed-mode delaminations are possible between the plies, the adhesive can debond, and the 
honeycomb sandwich core can crush. Each of these possible failure mechanisms has the potential to interact with any other mechanism. In order to account for each of these potential failure mechanisms and their many possible interactions, three progressive damage modeling methodologies are required, as described in the following subsection. Intraply damage is taken into account via a continuum damage mechanics (CDM) approach. Interply and adhesive damage modes are represented using layers of cohesive elements. Honeycomb core crushing is modeled using a specialized one-dimensional damage model. The next sub-sections briefly describe the progressive damage modeling techniques that are used in the present analysis.

\section{A. PDA Methods}

Continuum Damage Mechanics. Continuum damage mechanics is a PDA method that allows for the prediction of both damage initiation and damage evolution without having to make modifications to the original finite element mesh of the structure being analyzed. Rather than modeling cracks by the insertion of discrete discontinuities into the original finite element mesh, CDM approaches represent the effects of cracks by softening certain components of the constitutive stiffness tensor. Multiple damage modes are accounted for with a set of scalar damage state variables. After the initiation of a particular damage mode, the affected stiffness terms are softened according to relevant fracture toughness properties and the local characteristic element size. As a result, in order to accurately predict the initial linear elastic response, the initiation of damage, and the evolution of damage, it is necessary to have a set of material property data including the elastic moduli, strengths and fracture toughness values for each potential failure mechanism.

A combination of the LaRC03 [13] and LaRC04 [14] failure criteria is used for the CDM model predictions. The LaRC set of criteria consists of stress-based analytical equations that predict the onset of failure mechanisms such as matrix cracking, fiber fracture, and fiber kinking. The prediction of damage evolution is implemented through an updated version of the CDM approach originally proposed by Maimí et al. [15]. The improvements to the CDM approach that are relevant to this work include: (1) an extension of the set of failure criteria to account for threedimensional stress states, as well as extensions to the corresponding damage evolution laws and stiffness tensor degradation algorithms; (2) the development of a mixed-mode matrix damage evolution law [16]; and (3) the development of a new definition for the CDM effective stresses that allow for the simultaneous evolution of multiple damage modes. The details of this model are not presented herein.

Cohesive Zone Modeling. Cohesive elements are specialized nonlinear finite elements that are particularly useful to predict the initiation and evolution of cracks when the potential propagation paths are known a priori, e.g., Turon et al. [17]. The constitutive response of cohesive elements is determined through a cohesive law, defined in terms of local traction versus crack opening displacement. Prior to the prediction of damage initiation, a high cohesive stiffness keeps the crack surfaces closed. Upon satisfying a failure criterion, the stiffness properties of the element soften with further deformation until the element completely fails. The crack opening displacements corresponding to damage initiation and complete failure are dependent on the mode I and mode II strengths and fracture toughness values, as well as the local mode mixity. No in-plane loads are carried by cohesive elements.

Cohesive elements used to model composite delamination are usually set to have zero thickness, which requires very high, non-physical element stiffnesses. A different approach was used to model the adhesive layer: finite thickness cohesive elements were used to model both the elastic and the fracture processes in the material. Further details are provided in [7].

Core Crush Model. To represent the loss of stiffness of a honeycomb core as a result of crushing under compressive normal loads, a user-written one-dimensional damage model is used [2]. This damage model represents only the response of the normal direction of the core, and does not represent the transverse shear response of the honeycomb core. This damage model separates the compressive normal response of a honeycomb material into three parts: (1) the initial linear-elastic response, characterized by the Young's modulus; (2) the crushing of the core, during which the material has a negative tangent stiffness; and (3) the post-crush response, characterized by a significantly reduced modulus. In addition, the core crush damage model is capable of representing the unloading/reloading response of either a partially or fully crushed material.

\section{B. Finite Element Model}

A three dimensional finite element model of the joint specimen was developed in Abaqus 6.10-1 [18]. Userwritten subroutines are used to define the constitutive responses of the carbon/epoxy plies (via continuum damage mechanics) and the honeycomb core material, while Abaqus cohesive elements are used to model delamination between plies and the damage within the adhesive layer. Due to the convergence difficulties associated with 
progressive damage and the softening of damaged material, the models are solved with Abaqus/Explicit in double precision. Elements are not deleted after failing for both the CDM and cohesive damage methods.

The model of the tensile CSJ represents a panel that is $101.6 \mathrm{~mm}$ long and $6.35 \mathrm{~mm}$ wide. No plain strain conditions are assumed. A cross-section of the three-dimensional model is shown in Figure 7. Each ply of the facesheet and the splice is represented with a single layer of solid three-dimensional reduced integration elements, C3D8R. Between each ply, a layer of zero-thickness COH3D8 cohesive elements is included. The element size in the facesheets and splices along the x-direction is equal to the ply thickness (i.e., $0.19 \mathrm{~mm}$ ). For computational efficiency, the width of the model is limited to eight elements.

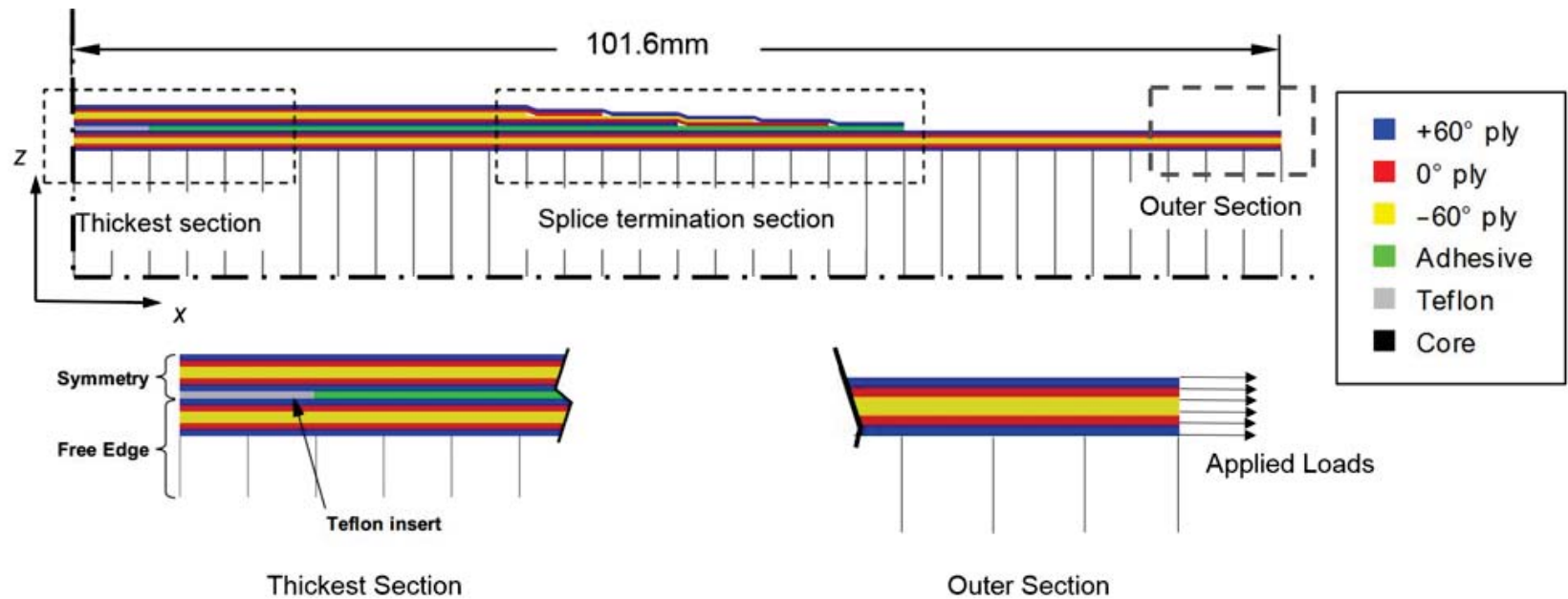

Figure 7. Cross-sectional view of the FE mesh for the conventional splice joint models and BCs.

The ply material properties for the carbon/epoxy facesheets and doublers are shown in Table 3. The elastic, thermal, and strength properties were provided by The Boeing Company [19]. The mode I and mode II matrix fracture toughness properties, GIc and GIIc, and the Benzeggagh-Kenane exponent $\eta$, are those of IM7/977-2 [20]. These properties are used for the prediction of matrix cracking and delaminations. Due to a lack of available fiber fracture toughness properties for IM7/977-2, properties from material system using the same fibers and a similar toughened epoxy matrix, IM7/8552, are used [21, 22].

Table 3. TE-1 Grade 190 Type 35 Carbon/Epoxy tape material properties.

Elastic Properties

\begin{tabular}{lrl}
\hline $\mathrm{E}_{11}$ & 142.0 & $\mathrm{GPa}$ \\
\hline $\mathrm{E}_{22}$ & 7.8 & $\mathrm{GPa}$ \\
\hline $\mathrm{E}_{33}$ & 7.8 & $\mathrm{GPa}$ \\
\hline $\mathrm{G}_{12}$ & 4.0 & $\mathrm{GPa}$ \\
\hline $\mathrm{G}_{13}$ & 4.0 & $\mathrm{GPa}$ \\
\hline $\mathrm{G}_{23}$ & 2.8 & $\mathrm{GPa}$ \\
\hline$v_{12}$ & 0.34 & \\
\hline$v_{13}$ & 0.34 & \\
\hline$v_{23}$ & 0.40 & \\
\hline
\end{tabular}

Thermal Properties

\begin{tabular}{lll}
\hline$\alpha_{11}$ & $3.60 \mathrm{e}-8$ & $/{ }^{\circ} \mathrm{C}$ \\
\hline$\alpha_{22}$ & $3.24 \mathrm{e}-5$ & $/{ }^{\circ} \mathrm{C}$ \\
\hline$\alpha_{33}$ & $3.24 \mathrm{e}^{-5}$ & $/{ }^{\circ} \mathrm{C}$ \\
\hline
\end{tabular}

\section{Fracture Properties}

\begin{tabular}{lrl}
\hline $\mathrm{G}_{\mathrm{XT}}{ }^{*}$ & 146.7 & $\mathrm{~N} / \mathrm{mm}$ \\
\hline $\mathrm{G}_{\mathrm{XC}}{ }^{*}$ & 106.3 & $\mathrm{~N} / \mathrm{mm}$ \\
\hline $\mathrm{G}_{\mathrm{II}}{ }^{*}$ & 0.26 & $\mathrm{~N} / \mathrm{mm}$ \\
\hline $\mathrm{G}_{\mathrm{IIc}}{ }^{*}$ & 1.40 & $\mathrm{~N} / \mathrm{mm}$ \\
\hline$\eta^{\ddagger}$ & 1.4 & \\
\hline $\mathrm{G}_{\mathrm{YC}}{ }^{\dagger}$ & 2.33 & $\mathrm{~N} / \mathrm{mm}$ \\
\hline
\end{tabular}

* IM7/8552 properties [21, 22].

$\uparrow$ Calculated

* IM7/977-2 properties [20].

The layer of adhesive between the facesheets and the splices is modeled using two coincident layers of finitethickness, bilinear COH3D8 cohesive elements with cohesive laws described in Section II. The Teflon insert near the joint gap is represented by setting the strength and fracture toughness properties of the adhesive elements to extremely low values, causing them to fail early in the analyses. Therefore, the elements representing the Teflon insert are able to carry compressive normal loads, but they do not resist shear or tensile normal loads. The honeycomb 
core is represented by a layer of two-node T3D2 truss elements, initially oriented in the z-direction. As a result, the transverse shear stiffness of the honeycomb core is neglected. However, because there is no significant bending applied to the CSJ model, it is determined that neglecting the honeycomb core transverse shear stiffness does not have a significant effect on the analysis results. The material properties for the honeycomb core are reported in Table 4.

Table 4. Hexcel CR III 1/8-5052-.0007 Honeycomb Material Properties.

\begin{tabular}{|c|c|c|c|c|c|}
\hline \multicolumn{3}{|c|}{ Elastic Properties } & \multicolumn{3}{|c|}{ Strength Properties } \\
\hline$E_{33}$ & [MPa] & 517.1 & $X_{33}$ & {$[\mathrm{kPa}]$} & 2068 \\
\hline$G_{\text {ribbon }}$ & [MPa] & 310.3 & & & \\
\hline$G_{\text {trans. }}$ & [MPa] & 151.7 & & & \\
\hline
\end{tabular}

The models are solved in two steps: the first one takes into account the thermal contraction of the carbon/epoxy material after curing by applying a temperature difference of $-152^{\circ} \mathrm{C}$ uniformly throughout the model, and the second one applies the tensile loads. Symmetry is assumed through the center of the honeycomb core and, during the thermal step, all the edges of the facesheet and the splice are left free. During the second step, displacements along the positive $\mathrm{x}$-direction are applied to the skin at $\mathrm{x}=101.6 \mathrm{~mm}$, as shown in Figure 7, while the nodes of the external splice at $\mathrm{x}=0$ are constrained in the $\mathrm{x}$-direction.

For computational efficiency, the time periods of the steps are selected to be as short as possible without inducing any significant dynamic forces. For the thermal step, it was found that a time period of 0.005 second is sufficiently long. For the loading step, it was found that a time period of 0.05 second represents the best compromise between computational efficiency and an approximation of a quasi-static solution. Loading rates are increased sinusoidally within each load step to reduce any applied accelerations and their corresponding model vibrations.

Variable mass scaling is used to decrease the solution time by increasing the minimum stable time increment to 2.e-07 second throughout the models (i.e., using less than 275,000 increments total, which is much less than the 2.e+06 increment limit recommended for double precision cases). The selection of this stable time increment, along with the material stiffnesses and element sizes used in the models, leads to initial model-wide changes in mass to be on the order of 50 to 150 times. Mass scaling factors are updated every 500 solution increments to account for any local changes in elemental stiffness, gradually increasing the mass of some elements as the solver proceeds.

\section{Results}

Tension tests were performed on two CSJs. The applied load and relative displacement were recorded during the tests [3]. The experimental and predicted load-displacement curves for the CSJ tension specimens are shown in Figure 8. The predicted peak load of the CSJ specimen is approximately $125 \mathrm{kN}$, compared to the experimentally observed strengths of 109 and $113 \mathrm{kN}$.

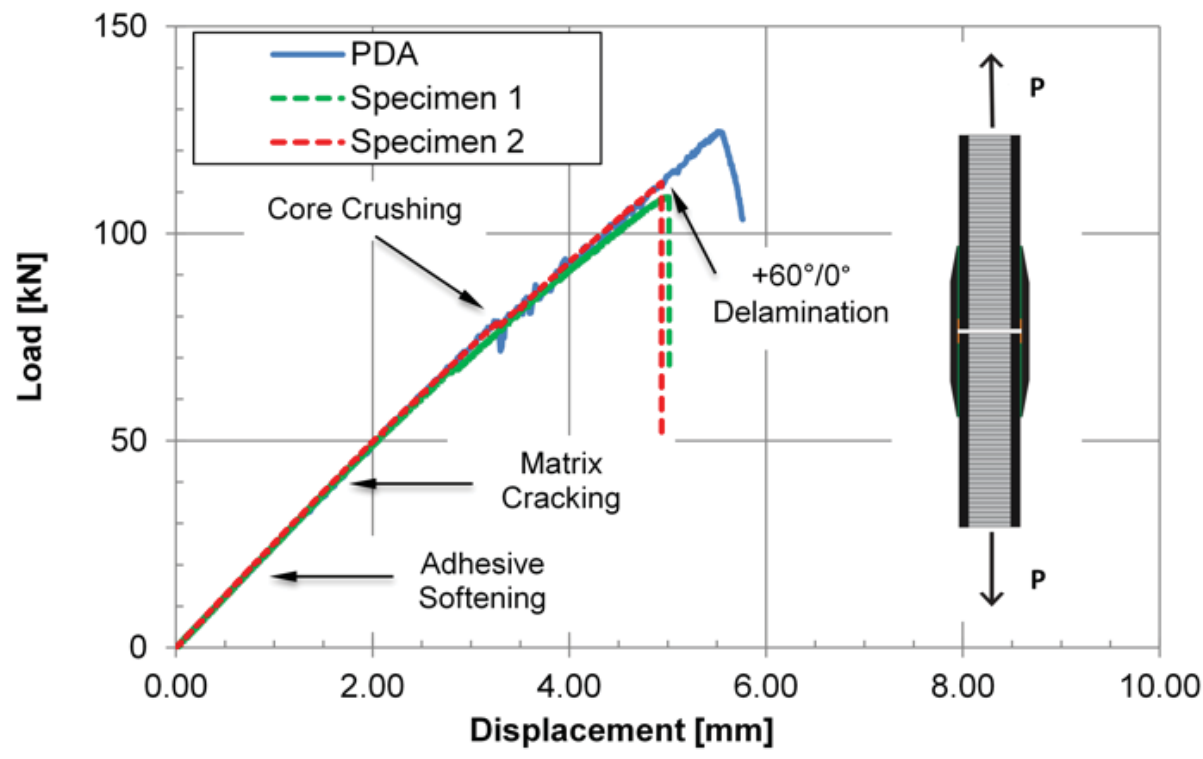

Figure 8. Predicted and experimental load-displacement responses of the CSJ.

9

American Institute of Aeronautics and Astronautics 
Prior to the predicted failure of the joint specimen, several instances of localized damage development occur in the model. At an applied load of approximately $15 \mathrm{kN}$, the adhesive layer begins to soften immediately ahead of the Teflon insert. The softening of the adhesive is a very gradual process, as expected due to the relatively large fracture toughness values determined during the material characterization. As a result, no significant loss of stiffness occurs due to the initial softening of the adhesive, as can be observed in Figure 8.

Localized matrix cracking is predicted to occur at two sites in the CSJ model between 40 and $45 \mathrm{kN}$ applied load: in the top $+60^{\circ}$ ply of the facesheet near the termination of the last $0^{\circ}$ doubler ply, and in the bottom $+60^{\circ}$ ply of the doubler near the end of the Teflon tape. These cracks initially have no effect on the global load-displacement response.

The bending of the facesheet near the end of the Teflon tape causes compressive loads in the honeycomb core in excess of its strength. At an applied load of $78 \mathrm{kN}$, the two rows of cells closest to the joint center in the model become crushed, as shown in Figure 9(a). Widespread matrix cracking is predicted in the facesheet at $79 \mathrm{kN}$. At 123 $\mathrm{kN}$, delaminations develop between the $+60^{\circ}$ and $0^{\circ}$ plies at the locations of the first two $+60^{\circ}$ matrix cracks, one of which is shown in Figure 9(b). The delaminations at both locations are approximately $1.3 \mathrm{~mm}$ long at this load level. The delaminations at each location grow stably until unstable delamination propagation occurs at a predicted peak load of $125 \mathrm{kN}$, cracking the matrix and adhesive where the two delaminations meet, Figure 9(c).Composite delamination at the $+60^{\circ} / 0^{\circ}$ interface and core crush were observed also experimentally, Figure 9(d).

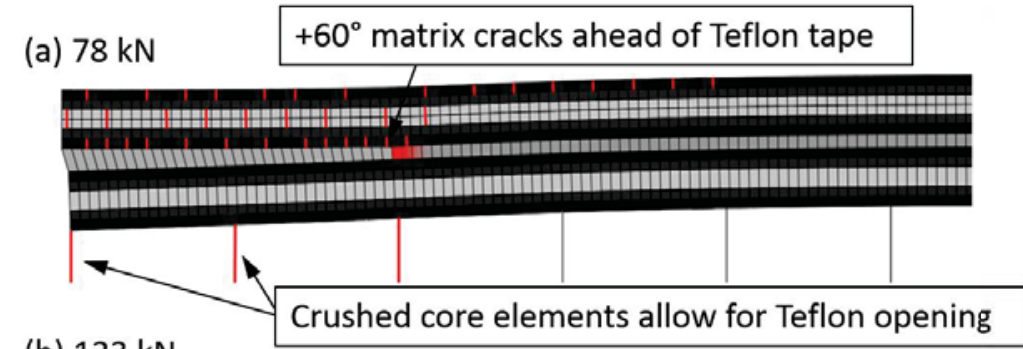

(b) $123 \mathrm{kN}$

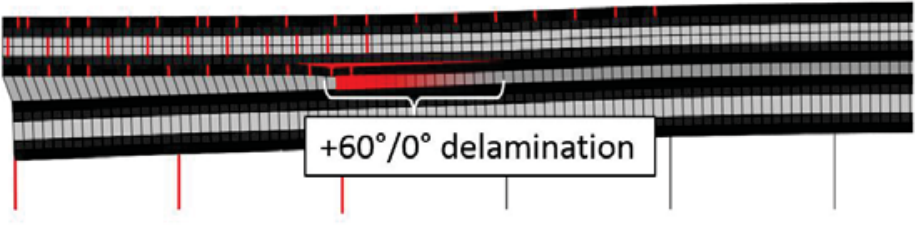

(c) $125 \mathrm{kN}$ (Peak Load)

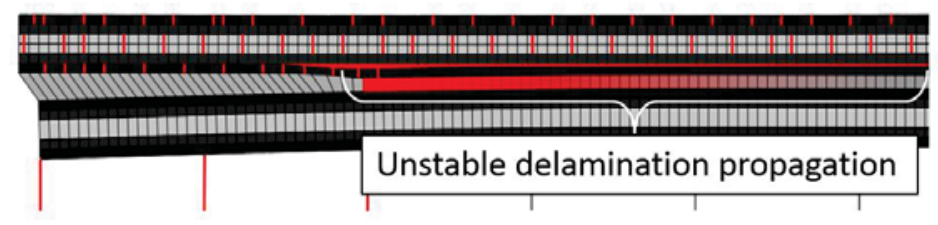

(d) CSJ Specimen Under Tensile Load

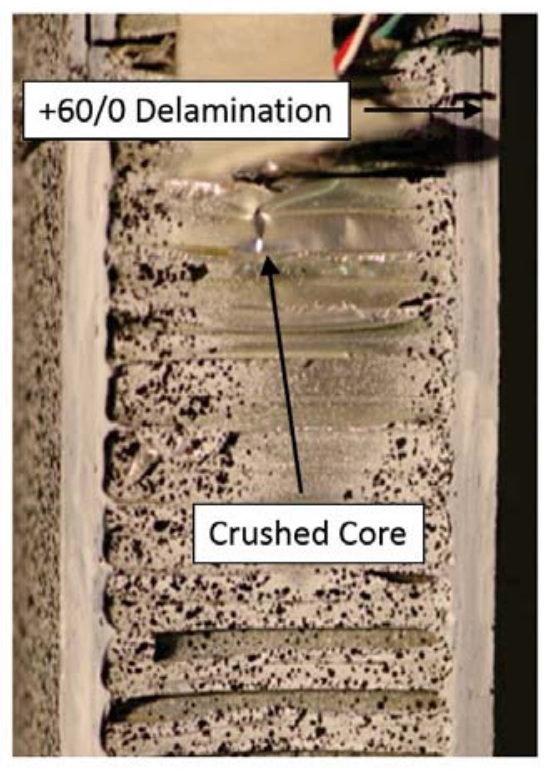

Figure 9. Failure process for conventional splice joint subjected to tensile loading, numerical and experimental.

\section{Concluding Remarks}

A complete numerical/experimental procedure was developed to establish the mechanical response (elastic, plastic and softening) of the structural adhesive layer used in a conventional splice joint (CSJ). The emphasis of the effort was on the evaluation of the cohesive laws for mode I and mode II delamination. These cohesive laws were obtained by numerical derivation of the J-integral functions for the DCB and ENF tests, and they were verified by correlation between the fracture experiments and the numerical models. The outcome the adhesive characterization was used within a progressive damage analysis (PDA) of the CSJ. The PDA was performed in Abaqus 6.10 using CDM methods to account for intralaminar failure mechanisms and CZM for interlaminar and adhesive failure mechanisms. The PDA successfully predicted the failure load, identified the failure modes, and provided information on the sequence of failure events of a CSJ subjected to tensile loads. 


\section{Acknowledgments}

The authors would like to acknowledge Dr. Choudry (STC STIEP Program Manager) and Dr. Stanley Smeltzer (Deputy Manager for the Space Launch System Program) for supporting the study. Acknowledgements are also reserved to Mr. Scott Splinter (NASA LaRC), Mr. William Johnston (NASA LaRC), and Dr. James Ratcliffe (NASA LaRC) for their assistance during the experimental tests.

\section{References}

[1] M. D. Banea and L. F. M. da Silva, "Adhesively Bonded Joints in Composite Materials: An Overview," vol. 223 Part L: J, 2008.

[2] J. G. Ratcliffe, M. W. Czabaj and W. C. Jackson, "A Model for Simulating the Response of Aluminum Honeycomb Structure to Transverse Loading.," in 2012 American Society for Composites 27th Technical Conference; 15th US-Japan Conference on Composite Materials Meeting, Arlington, VA, 2012.

[3] S. Lin, S. C. Splinter, C. Tarkenton, D. A. Paddock, S. S. Smeltzer, S. Ghose, J. C. Guzman, D. J. Sutkus and D. A. McCarville, "Fabrication and Testing of Durable Redundant and Fluted-Core Joints for Composite Sandwich Structures," in Society for the Advancement of Materials and Process Engineering, Long Beach, CA, 2013.

[4] T. D. Breitzman, E. V. Iarve, B. M. Cook, G. A. Schoeppner and R. P. Lipton, "Optimization of a Composite Scarf Repair Patch Under Tensile Loading,” Composites: Part A, pp. 1921-1930, 2009.

[5] "Standard Test Method for Mixed Mode I-Mode II Interlaminar Fracture Toughness of Unidirectional Fiber Reinforced Polymer Matrix Composites," ASTM standard D6671/D6671M, 2006.

[6] M. L. Benzeggagh and M. Kenane, "Measurement of Mixed-Mode Delamination Fracture Toughness of Unidirectional Glass/Epoxy Composites With Mixed-Mode Bending Apparatus," Composite Science and Technology, vol. 56, pp. 439-449, 1996.

[7] D. Girolamo, "Progressive Damage Analysis of Bonded Composite Joints," M.Sc. Thesis TU Delft, 2012.

[8] J. R. Rice, "A Path Independent Integral and the Approximate Analysis of Strain Concentration by Notches and Cracks," Journal of Applied Mechanics, vol. 35, pp. 145-153, 1968.

[9] K. Leffler, K. S. Alfredsson and U. Stigh, "Shear Behaviour of Adhesive Layers," International Journal of Solids and Structures, vol. 44, pp. 530-545, 2007.

[10] J. L. Högberg, B. F. Sørensen and U. Stigh, "Constitutive Behaviour of Mixed Mode Loaded Adhesive Layer," Int. J. Solids Structures, vol. 44, no. 25-26, pp. 8335-8354, 2007.

[11] A. Turon, P. P. Camanho, J. Costa and J. Renart, "Accurate Simulation of Delamination Growth Under MixedMode Loading Using Cohesive Elements: Definition of Interlaminar Strengths and Elastic Stiffness," Composite Structures, vol. 92, pp. 1857-1864, 2010.

[12] J. R. Reeder, K. Demarco and K. S. Whitley, "The Use of Doubler Reinforcement in Delamination Toughness Testing," Composites: Part A, vol. 35, pp. 1337-1344, 2004.

[13] C. G. Dávila and P. P. Camanho, "Failure Criteria for FRP Laminates in Plane Stress," NASA TM 212663, Nov 01, 2003.

[14] S. T. Pinho, C. G. Dávila, P. P. Camanho, L. Iannucci and P. Robinson, "Failure Models and Criteria for FRP Under In-Plane or Three-Dimensional Stress States Including Shear Nonlinearity," NASA TM 213530, 2005.

[15] P. Maimí, P. P. Camanho, J.-A. Mayugo and C. G. Dávila, "A Thermodynamically Consistent Damage Model for Advanced Composites," NASA TM 214282, 2006.

[16] F. A. Leone and C. G. Dávila, "Mixed-Mode Matrix Damage Evolution in Continuum Damage Mechanics," in 16th International Conference on Composite Structures, Porto, Portugal, 23-30 June 2011.

[17] A. Turon, P. P. Camanho, J. Costa and C. G. Dávila, "A Damage Model for the Simulation of Delamination in Advanced Composites Under Variable-Mode Loading," Mechanics of Materials, vol. 38, p. 1072-1089, 2006.

[18] Manual, Abaqus Users. "Version 6.10-1." Dassault Systémes Simulia Corp., Providence, RI.

[19] S. Ghose, The Boeing Company. Personal communication.

[20] J.R. Reeder, “3D Mixed-Mode Delamination Fracture Criteria-An Experimentalist's Perspective”. 21st Annual Technical Conference of the American Society for Composites. Dearborn, MI, September, 2006. 
[21] P.P. Camanho, P. Maimí, C.G. Dávila, "Prediction of size effects in notched laminates using continuum damage mechanics". Composites Science and Technology 2007;67:2715-2727.

[22] G. Catalanotti, P.P. Camanho, J. Xavier, C.G. Dávila, A.T. Marques, "Measurement of resistance curves in the longitudinal failure of composites using digital image correlation". Composites Science and Technology 2010;70:1986-1993. 